\title{
Do Patient Concerns About Antihypertensive Use For Dementia Prevention Vary By Current Use Of Antihypertensive?
}

This article was published in the following Dove Press journal: Patient Preference and Adherence

\author{
Woojung Lee $\mathbb{D}^{\prime}$ \\ Shelly L Gray' \\ Douglas Barthold' \\ Paul K Crane ${ }^{2}$ \\ Eric B Larson ${ }^{3}$ \\ Zachary A Marcum (D) \\ 'School of Pharmacy, University of \\ Washington, Seattle, WA 98195, USA; \\ ${ }^{2}$ School of Medicine, University of \\ Washington, Seattle, WA 98104, USA; \\ ${ }^{3}$ Kaiser Permanente Washington Health \\ Research Institute, Seattle, WA \\ 98I0I, USA
}

Correspondence: Zachary A Marcum Department of Pharmacy, School of Pharmacy, University of Washington, 1959 NE Pacific St, Box 357630, Seattle, WA 98102, USA

$\mathrm{Tel}+1$ 206-685-2559

Fax + 206-543-3835

Email zmarcum@uw.edu

Twitter@zacharyamarcum
Purpose: Antihypertensives may have effects on the brain beyond blood pressure lowering. Ongoing clinical trials aim to evaluate the effectiveness of approved antihypertensives in preventing dementia, including patients with and without hypertension. In order for a dementia prevention strategy using antihypertensives to be effective, it is critical to understand patient concerns about this strategy in both users and non-users of antihypertensives. Thus, this study examined the association between current use of antihypertensive and having concerns about using an antihypertensive as a dementia prevention strategy, as well as sociodemographic factors associated with concerns.

Patients and methods: Cross-sectional, self-administered, web-based survey was conducted among 1661 patients in a large health system in January 2018. Participants reported whether they were currently taking an antihypertensive (yes/no), and what types of hypothetical concerns they have about the idea of taking an antihypertensive to prevent dementia (yes/no, for each of 7 concerns). Associations between the two variables were assessed via logistic regression, and odds ratios with $95 \%$ confidence intervals were calculated.

Results: Most respondents were female (77\%), 51-70 years of age (64\%), and white (89\%), with $30 \%$ reporting current antihypertensive use. Compared to current users, non-users were more likely to report the five following concerns: side effects from the medication, hassle to take medications, lack of evidence, not wanting to use medications, and already having normal/low blood pressure. Non-users were also less likely to report having no concerns (adjusted $\mathrm{OR}=0.3 ; 95 \% \mathrm{CI}=0.2-0.4$ ) compared to current users. Younger age and lower income were associated with having more concerns.

Conclusion: Patients not currently using an antihypertensive are more likely to have concerns about using an antihypertensive for dementia prevention, compared to current antihypertensive users. Patient perspectives are important to consider for the implementation of dementia prevention strategies.

Keywords: dementia, antihypertensives, primary prevention, patient concerns, patient perspectives

\section{Introduction}

Ongoing clinical trials, such as the Mechanistic Potential of Antihypertensives in Preclinical Alzheimer's Trial (HEART), aim to evaluate whether approved antihypertensives can be repurposed as a dementia prevention strategy. ${ }^{1-4}$ Such trials are supported by a large body of literature from both animals and humans on the role of the renin-angiotensin system in dementia development. ${ }^{4-14}$ Of note, some 
antihypertensives are thought to have brain protectant effects beyond their role in decreasing blood pressure. ${ }^{1,2}$ Given this, individuals with and without hypertension could possibly benefit from antihypertensive use to reduce the risk of dementia.

Despite these potential benefits, little is known about people's specific concerns (e.g., side effects such as hypotension) regarding the use of antihypertensives as a dementia prevention strategy. We previously published results from a mixed-method study showing that the vast majority of respondents currently taking an antihypertensive reported that they would be willing to take that specific antihypertensive starting as early as mid-life if it were shown to prevent or delay dementia. ${ }^{15}$ Moreover, those currently taking an antihypertensive were more likely to report no concerns compared to those not taking an antihypertensive. This finding suggests differential beliefs toward this emerging dementia prevention strategy based on current antihypertensive use; however, this association may be confounded by individual characteristics. ${ }^{15}$ Thus, the current analysis aims to examine the association between current use of an antihypertensive and having concerns about using an antihypertensive as a dementia prevention strategy, adjusting for potential confounders. In addition, we examine if those concerns vary by sociodemographic characteristics.

\section{Materials And Methods Study Design}

This cross-sectional study used data obtained from a webbased survey. The survey includes sociodemographic characteristics of members of Kaiser Permanente Washington, an integrated healthcare delivery system in Washington State, as well as responses from the following three domains: (1) brain health and dementia prevention; (2) medications as risk or protective factors for dementia; and (3) antihypertensive use as a potential dementia prevention strategy. Development of the survey has been previously described. ${ }^{16}$

\section{Participants}

Study participants were sampled in January 2018 through Northwest Health News, a monthly electronic newsletter emailed to Kaiser Permanente Washington members. The newsletter included information on the study and a link to direct interested participants to the web-based survey via the newsletter. Eligible participants were those aged 18 or older, were Kaiser Permanente Washington members, and could read and write English. A total of 1661 people completed the survey and were included in the analysis. The Institutional Review Board at the Kaiser Permanente Washington Health Research Institute approved all study materials and procedures.

\section{Measures}

For this analysis, the primary independent variable was self-reported current use of an antihypertensive. To operationalize this variable, we used an item from the third survey domain that asks all participants "Are you currently taking a medication for your blood pressure?" Participants responded either yes or no.

Our outcome variables of interest - concerns about taking antihypertensives as a dementia prevention strategy - were also collected from the third survey domain. All participants were asked, "What main concerns do you have about the idea of taking a blood pressure medication for the rest of your life in order to possibly prevent Alzheimer's disease or other forms of Dementia?" Participants were then asked to select all that apply from eight different options as follows: (1) side effects from the medication; (2) hassle to take medication every day; (3) expense/cost of the medication; (4) inability to remember to take medication when I should; (5) lack of evidence showing that this will reduce my risk; (6) do not want to use a medication; (7) my blood pressure is already normal or low; and (8) I have no concerns. Participants responded either yes or no.

Sociodemographic factors - sex, age, race, ethnicity, education, and annual household income - were included to adjust for potential confounding and to be investigated for association with the outcome variables.

\section{Data Analysis}

Frequency distributions were used to describe respondent characteristics. Statistical differences in participants' demographic factors between those who reported currently taking antihypertensives versus those who did not were compared using a z-test. ${ }^{17}$ To examine whether current use of antihypertensives was associated with reporting each individual concern, eight separate logistic regression models were fitted for each outcome, adjusted for sex, age, race, ethnicity, education, and annual household income. For each of these concerns (models), an odds ratio and a 95\% confidence interval were calculated, contrasting nonusers (of antihypertensives) relative to current users. To 
examine the association between sociodemographic covariates and the outcome variables, joint significance of each covariate was tested using a Wald test, with p-value reported. Odds ratios comparing each subgroup with the corresponding reference group were estimated using partial F-tests. Significance level was set at 0.05 . All analyses were conducted using STATA/MP software, version 14.2.

\section{Results}

\section{Respondent Characteristics}

Of the 1661 participants, $76.7 \%$ identified as female and $63.5 \%$ were aged $51-70$ years. The majority were white $(86.2 \%)$ and non-Hispanic (91.0\%) (Table 1). Approximately one-third of respondents reported current use of antihypertensives $(\mathrm{n}=505 ; 30.4 \%)$. When compared to current users of antihypertensive medication $(\mathrm{n}=505)$, a higher proportion of non-users were male, younger, more educated, and had higher annual income (Supplemental Table A1).

\section{Concerns By Antihypertensive Use}

Logistic regression models adjusting for sociodemographic factors showed that non-users were significantly more likely to report five types of concerns: side effects from medications $(\mathrm{OR}=2.1,95 \% \mathrm{CI}: 1.6,2.8)$, hassle of taking medications every day $(\mathrm{OR}=2.9,95 \% \mathrm{CI}: 1.7,4.9)$, lack of evidence $(\mathrm{OR}$ $=2.3,95 \%$ CI: $1.8,3.0$ ), do not want to use a medication (OR $=7.6,95 \%$ CI: $3.3,17.5)$, and normal/low blood pressure $(\mathrm{OR}=40.3,95 \%$ CI: 24.8, 65.5) (Table 2). An adjusted logistic regression model also demonstrated that the likelihood of "having no concerns" was significantly lower among non-users of antihypertensives (OR $=0.3,95 \%$ CI: $0.2,0.4)$ compared to current users.

\section{Sociodemographic Characteristics Associated With Concerns}

Among all sociodemographic characteristics, age, income, sex, and race were associated with having certain concerns, with other sociodemographic variables and current use of an antihypertensive controlled for (Table 3). Older respondents were less likely to have concerns about side effects from medications $(p=0.009)$, hassle of taking medications $(p<0.001)$, and costs of medications $(p<0.001)$. Higher income was associated with having fewer concerns about side effects from medications ( $p=0.012)$, costs of medications $(p<0.001)$, and inability to remember to take medications when they should $(p=0.023$ ). Lastly, females reported fewer concerns about lack of evidence $(p=0.049)$ and not wanting to
Table I Survey Respondent Characteristics ( $N=1661)$

\begin{tabular}{|c|c|}
\hline & $\begin{array}{l}\text { Respondents } \\
\text { No. (\%) }\end{array}$ \\
\hline \multicolumn{2}{|l|}{ Sex } \\
\hline Female & $1274(76.7)$ \\
\hline Male & $317(19.1)$ \\
\hline Non-binary & $3(0.2)$ \\
\hline Prefer not to answer/skipped & $67(4.0)$ \\
\hline \multicolumn{2}{|l|}{ Age, y } \\
\hline $21-40$ & $94(5.7)$ \\
\hline $4 I-50$ & $149(9.0)$ \\
\hline $51-60$ & $392(23.6)$ \\
\hline $6 \mathrm{I}-70$ & $662(39.9)$ \\
\hline $71-80$ & $300(18.1)$ \\
\hline$\geq 81$ & $59(3.6)$ \\
\hline Skipped & $5(0.3)$ \\
\hline \multicolumn{2}{|l|}{ Race } \\
\hline White & $1432(86.2)$ \\
\hline Asian & $35(2.1)$ \\
\hline Black or African American & $17(1.0)$ \\
\hline Other & $69(4.2)$ \\
\hline Prefer not to answer/skipped & $108(6.5)$ \\
\hline \multicolumn{2}{|l|}{ Ethnicity } \\
\hline Non-Hispanic & $1512(91.0)$ \\
\hline Hispanic & $42(2.5)$ \\
\hline Don't know/prefer not to answer/skipped & $107(6.5)$ \\
\hline \multicolumn{2}{|l|}{ Education } \\
\hline High school graduate or lower & $73(4.4)$ \\
\hline Some college & $407(24.5)$ \\
\hline College graduate & $412(24.8)$ \\
\hline Some post-graduate & $178(10.7)$ \\
\hline Post-graduate & $530(31.9)$ \\
\hline Prefer not to answer/skipped & $61(3.7)$ \\
\hline \multicolumn{2}{|l|}{ Annual household income, $\$$} \\
\hline$<35,000$ & $151(9.1)$ \\
\hline $35,000-49,999$ & $188(\mid 1.3)$ \\
\hline $50,000-74,999$ & $314(18.9)$ \\
\hline 75,000-99,999 & $291(17.5)$ \\
\hline$\geq 100,000$ & $404(24.3)$ \\
\hline Don't know/prefer not to answer/skipped & $313(18.9)$ \\
\hline \multicolumn{2}{|l|}{ Current use of antihypertensives } \\
\hline Current use & $505(30.4)$ \\
\hline Non-use & $115 \mid(69.3)$ \\
\hline Prefer not to answer & $5(0.3)$ \\
\hline
\end{tabular}

use a medication $(p=0.019)$, but were more likely to be worried about their blood pressure already being normal or low $(p=0.001)$ compared to males. Asian respondents appeared to have more concerns compared to Whites for certain concerns: hassle to take medications $(p=0.027)$, 
Table 2 Association Between Antihypertensive Use And Concerns About Antihypertensive Use As A Dementia Prevention Strategy (Non-Current Users Vs Current Users; $\mathrm{N}=1661$ )

\begin{tabular}{|c|c|c|c|c|}
\hline Concerns (Dependent Variables) & $\begin{array}{l}\text { Number Of People With } \\
\text { Concerns (\%) }\end{array}$ & $\begin{array}{l}\text { Adjusted Odds } \\
\text { Ratio }(O R)^{a}\end{array}$ & $\begin{array}{l}95 \% \text { Confidence } \\
\text { Interval Of OR }\end{array}$ & p-Value \\
\hline Side effects from the medication & $1,253(75.4)$ & 2.1 & $(1.6,2.8)$ & $<0.001$ \\
\hline Hassle to take medication every day & $195(11.7)$ & 2.9 & $(1.7,4.9)$ & $<0.001$ \\
\hline Expense/cost of the medication & $727(43.8)$ & I.I & $(0.8,1.4)$ & 0.63 \\
\hline $\begin{array}{l}\text { Inability to remember to take medication } \\
\text { when I should }\end{array}$ & $78(4.7)$ & 1.5 & $(0.8,2.9)$ & 0.23 \\
\hline $\begin{array}{l}\text { Lack of evidence showing that this will } \\
\text { reduce my risk }\end{array}$ & $964(58.0)$ & 2.3 & $(1.8,3.0)$ & $<0.001$ \\
\hline Do not want to use a medication & $123(7.4)$ & 7.6 & $(3.3,17.5)$ & $<0.001$ \\
\hline My blood pressure is already normal or low & $775(46.7)$ & 40.3 & $(24.8,65.5)$ & $<0.001$ \\
\hline I have no concerns & $175(10.5)$ & 0.3 & $(0.2,0.4)$ & $<0.001$ \\
\hline
\end{tabular}

Notes: ${ }^{a}$ Odds ratios and $95 \%$ confidence intervals calculated using separate logistic regression models adjusted for sex, age, race, ethnicity, education, and annual household income.

inability to remember $(p=0.020)$, and not wanting to use medications $(p=0.029)$. However, these results should be interpreted with caution because of the small number of Asian respondents $(\mathrm{n}=35)$.

\section{Discussion}

This cross-sectional study of a web-based survey demonstrated that those who are not currently taking antihypertensives are more likely to have concerns about the idea of using antihypertensives as a dementia prevention strategy than current antihypertensive users, after adjusting for sociodemographic variables. In addition, we found that age, income, and sex were associated with the likelihood of having certain concerns regardless of current use of antihypertensives. We extend our prior work and determine that patients' concerns about this emerging dementia prevention strategy differ significantly by current antihypertensive use and sociodemographics.

For concerns about potential side effects, hassle of taking medications, and lack of efficacy evidence, the likelihood of having these concerns was about two to three times greater in non-users of antihypertensives compared to current users. The gap between current users and non-users was much greater, however, for the concern of not wanting to use a medication and the concern about blood pressure being already normal or low. Specifically, people not currently using an antihypertensive had greater likelihood of expressing these concerns compared to current users. This result indicates that people with normal blood pressure (i.e., not taking antihypertensives) call for strong justification of the need to take antihypertensives for dementia prevention in addition to the evidence for efficacy and safety of this strategy. This is a valid concern due to the risk of hypotension from antihypertensive use. ${ }^{18}$ Thus, clinical trials that aim to test this potential dementia prevention strategy might require additional recruitment efforts for enrolling individuals without hypertension.

It should be noted that sociodemographic characteristics such as age, annual household income, and sex were associated with different concerns about this strategy. Younger respondents appeared to have more reservations than older respondents about potential side effects, the hassle of taking a medication every day, and costs of the medication. This finding is likely explained by younger adults having more skepticism about dependence on medications to prevent diseases that may or may not develop in the distant future, which makes them less willing to accept the hassle and expense. ${ }^{19,20}$ In addition, we found that concerns regarding side effects, costs of medications, and inability to remember to take medications tended to be more common among people with lower income. Personal and contextual factors such as fear of harm from medication, complicated instructions, and less access to medications have shown to be major barriers to medication adherence in those with low income. ${ }^{21}$ Patient-centered discussions between patients, their family members, and health care providers on these potential concerns may improve patient engagement in this strategy. 
Table 3 Sociodemographic Characteristics Associated With Concerns About Antihypertensive Use As A Dementia Prevention Strategy (Values Reported: Odds Ratios; $\mathrm{N}=1661$ )

\begin{tabular}{|c|c|c|c|c|c|c|c|c|}
\hline \multirow{3}{*}{$\begin{array}{l}\text { Independent } \\
\text { Variables }^{\text {e }}\end{array}$} & \multicolumn{8}{|c|}{ Concerns $^{d}$} \\
\hline & $\mathbf{a}$ & b & c & d & e & $\mathbf{f}$ & $\mathbf{g}$ & h \\
\hline & $\begin{array}{l}\text { Side } \\
\text { Effects }\end{array}$ & Hassle & Expense & $\begin{array}{l}\text { Inability To } \\
\text { Remember }\end{array}$ & $\begin{array}{l}\text { Lack Of } \\
\text { evidence }\end{array}$ & $\begin{array}{l}\text { Not Wanting } \\
\text { To Use Med }\end{array}$ & $\begin{array}{l}\text { Normal Or Low } \\
\text { Blood Pressure }\end{array}$ & $\begin{array}{l}\text { No } \\
\text { Concern }\end{array}$ \\
\hline Sex ${ }^{f}$ & - & - & - & - & - & - & - & - \\
\hline Male & Ref & Ref & Ref & Ref & Ref & Ref & Ref & Ref \\
\hline Female & 0.93 & 0.66 & 1.10 & 0.69 & $0.75^{\mathrm{a}}$ & $0.53^{\mathrm{a}}$ & $1.77^{\mathrm{b}}$ & 1.01 \\
\hline$p$-value ${ }^{g}$ & 0.68 & 0.06 & 0.51 & 0.24 & 0.05 & 0.02 & 0.001 & 0.97 \\
\hline Age $(\text { year })^{\mathrm{h}}$ & - & - & - & - & - & - & - & - \\
\hline$\leq 50$ & Ref & Ref & Ref & Ref & Ref & Ref & Ref & Ref \\
\hline $5 I-60$ & 0.75 & $0.59^{\mathrm{a}}$ & $0.65^{\mathrm{a}}$ & $0.38^{\mathrm{a}}$ & 0.94 & 0.77 & 1.19 & 1.24 \\
\hline $6 I-70$ & $0.58^{\mathrm{a}}$ & $0.4 \mathrm{I}^{\mathrm{b}}$ & $0.38^{c}$ & $0.45^{\mathrm{a}}$ & 0.93 & 0.80 & 1.15 & $2.04^{\mathrm{a}}$ \\
\hline $7 I-80$ & $0.5 \mathrm{I}^{\mathrm{b}}$ & $0.32^{\mathrm{b}}$ & $0.16^{\mathrm{c}}$ & 0.54 & 1.02 & 0.82 & 1.53 & 1.85 \\
\hline$\geq 81$ & $0.29^{\mathrm{b}}$ & Omitted & $0.13^{c}$ & 0.50 & 0.94 & 0.58 & 0.67 & $3.55^{\mathrm{b}}$ \\
\hline$p$-value ${ }^{g}$ & 0.01 & $<0.001$ & $<0.001$ & 0.11 & 0.98 & 0.92 & 0.36 & 0.06 \\
\hline Race & - & - & - & - & - & - & - & - \\
\hline White & Ref & Ref & Ref & Ref & Ref & Ref & Ref & Ref \\
\hline Black & 0.62 & 0.76 & 1.55 & Omitted & 1.54 & Omitted & 0.87 & 1.39 \\
\hline Asian & 0.50 & $2.65^{\mathrm{a}}$ & 0.86 & $3.57^{\mathrm{a}}$ & 0.94 & $2.87^{\mathrm{a}}$ & 2.48 & 0.38 \\
\hline Other & 1.19 & 1.53 & 1.38 & 1.15 & 1.02 & 1.20 & 1.14 & 0.63 \\
\hline$p$-value ${ }^{g}$ & 0.34 & 0.11 & 0.62 & 0.06 & 0.93 & 0.11 & 0.41 & 0.64 \\
\hline Ethnicity & - & - & - & - & - & - & - & - \\
\hline Non-hispanic & Ref & Ref & Ref & Ref & Ref & Ref & Ref & Ref \\
\hline Hispanic & 1.39 & 0.94 & 1.16 & 0.42 & 1.18 & 2.14 & 0.46 & 1.27 \\
\hline$p$-value ${ }^{g}$ & 0.47 & 0.90 & 0.72 & 0.43 & 0.66 & 0.17 & 0.05 & 0.67 \\
\hline Education & - & - & - & - & - & - & - & - \\
\hline$\leq$ High school graduate & Ref & Ref & Ref & Ref & Ref & Ref & Ref & Ref \\
\hline Some college & 1.12 & 0.76 & $\mathrm{I} .44$ & 1.13 & 1.15 & 0.71 & 0.67 & 0.88 \\
\hline College graduate & 1.48 & 0.88 & 1.19 & 1.00 & 1.34 & 1.15 & 0.99 & 0.51 \\
\hline Some post-graduate & 1.69 & 1.27 & 1.57 & 1.03 & 1.25 & 2.04 & 0.99 & 0.79 \\
\hline Post graduate degree & 1.77 & 1.09 & 1.22 & 0.81 & 1.43 & 1.10 & 0.96 & 0.56 \\
\hline$p$-value ${ }^{g}$ & 0.09 & 0.55 & 0.46 & 0.90 & 0.57 & 0.11 & 0.26 & 0.13 \\
\hline Income (\$) & - & - & - & - & - & - & - & - \\
\hline$<35,000$ & Ref & Ref & Ref & Ref & Ref & Ref & Ref & Ref \\
\hline $35,000-49,999$ & 0.78 & 0.57 & 0.98 & 0.54 & 1.07 & 0.63 & $1.80^{\mathrm{a}}$ & 1.31 \\
\hline $50,000-74,999$ & 0.75 & 0.67 & 0.67 & 0.60 & 0.86 & 0.52 & 1.14 & 1.40 \\
\hline $75,000-99,999$ & 0.89 & 0.80 & $0.47^{\mathrm{b}}$ & $0.37^{\mathrm{a}}$ & 1.09 & 0.57 & 1.37 & 1.10 \\
\hline$\geq 100,000$ & $0.50^{\mathrm{b}}$ & 0.62 & $0.34^{\mathrm{c}}$ & $0.28^{\mathrm{b}}$ & 0.81 & $0.38^{\mathrm{a}}$ & 1.54 & $2.04^{\mathrm{a}}$ \\
\hline$p$-value ${ }^{g}$ & 0.01 & 0.50 & $<0.001$ & 0.02 & 0.33 & 0.16 & 0.17 & 0.10 \\
\hline
\end{tabular}

Notes: ${ }^{a} \mathrm{p}<0.05,{ }^{b}<<0.01,{ }^{c} p<0.001$; ${ }^{d}(a)$ Side effects from the medication, (b) Hassle to take medication every day, (c) Expense/cost of the medication, (d) Inability to remember to take medication when I should, (e) Lack of evidence showing that this will reduce my risk, (f) Do not want to use a medication, (g) My blood pressure is already normal or low, and (h) I have no concerns; ${ }^{\mathrm{e}}$ Current use of antihypertensives was included in each model as an independent variable; ${ }^{\mathrm{f}}$ Those who identified themselves as non-binary were omitted due to a very small sample size; ${ }^{\mathrm{g}} \mathrm{p}$-value from Wald test, adjusted for all other covariates; ${ }^{\mathrm{h}} \mathrm{Age}$ categories below 40 and $4 \mathrm{I}-50$ were combined; 'Dummy variables were omitted due to a perfect correlation with the outcome variable.

This study is not without limitations. Our study results may not generalize to other populations, given that this survey was implemented in a convenience sample of adults from a single region in the US. Since older nonHispanic white females were overrepresented in this study sample, care should be taken when applying these results 
to a population with different sociodemographic distributions. There could be a potential selection bias if the respondents of survey were systematically different from non-respondents. Future surveys should examine people's concerns about this strategy in more generalizable groups that include more diverse sociodemographic characteristics. Furthermore, past medication history, which can possibly affect perspectives of medication use, was not collected and thus not adjusted for in our analysis. There is a possibility that non-users of antihypertensives have taken them in the past, which our survey did not capture. In addition, people with different diseases or past medication experience might have dissimilar concerns of this strategy. There is also a potential of residual bias since duration of antihypertensive use may influence concerns. Future studies should explore varying concerns among people, considering their disease and medication history, including duration of medication use. We were also unable to calculate a survey response rate since we could not measure how many people opened the electronic newsletter. However, we viewed results as hypothesis-generating for future research efforts.

\section{Conclusion}

In conclusion, patients not currently using an antihypertensive are more likely to have concerns about using an antihypertensive for dementia prevention, compared to current users. Specifically, non-users of antihypertensives expressed concerns about already having normal or low blood pressure as well as potential efficacy and safety issues. While not surprising, these patient perspectives can help inform the implementation of this evolving dementia prevention strategy.

\section{Ethics Approval And Informed Consent}

The Institutional Review Board at the Kaiser Permanente Washington Health Research Institute approved all study materials and procedures. Participants provided consent upon completing the survey.

\section{Data Availability}

Data are available from the corresponding author upon request.

\section{Acknowledgements}

The authors would like to thank Jane McNamee for her assistance with survey deployment, Kelly Hansen for her assistance with project management, and the members of the Kaiser Permanente Washington Senior Caucus for their important feedback on the initial survey. The sponsor had no role in the design, methods, subject recruitment, data collection, analysis, and preparation of this paper. Results from this manuscript were previously presented at the ISPOR 2019 annual conference in New Orleans, LA, May 2019. The abstract of this manuscript has been published in Value in Health: Lee W, Gray S, Barthold D, et al PIH68 do patient concerns about antihypertensive use as a dementia prevention strategy vary by current use of antihypertensive medication? Value in Health, 2019;22:S193S194.

\section{Author Contributions}

All authors listed meet the IMCJE guidelines for authorship. All authors contributed to data analysis, drafting, or revising the article, gave final approved of the version to be published and agree to be accountable for all aspects of the work.

\section{Funding}

This work was supported by the Agency for Healthcare Research \& Quality (Grant K12HS022982).

\section{Disclosure}

Dr Doug Barthold reports personal fees from Omada Health for serving as an analysis consultant for a scientific analysis of Omada's digital diabetes app., outside the submitted work. Dr Paul K Crane reports grant from Eisai for consulting and travel fees for lecturing at Eisai on cognitively defined Alzheimer's disease subtypes in 2018, outside the submitted work. The authors report no other conflicts of interest in this work.

\section{References}

1. Wharton W, Goldstein FC, Tansey MG, et al. Rationale and design of the mechanistic potential of antihypertensives in preclinical Alzheimer's (HEART) trial. $J$ Alzheimers Dis. 2018;61:1-10. doi:10.3233/JAD-170628

2. Dacks PA, Armstrong JJ, Brannan SK, et al. A call for comparative effectiveness research to learn whether routine clinical care decisions can protect from dementia and cognitive decline. Alzheimers Res Ther. 2016;8:33. doi:10.1186/s13195-016-0200-3

3. Van Middelaar T, van Nught LA, van Gool WA, et al. Blood pressurelowering interventions to prevent dementia: a systematic review and meta-analysis. J Hypertens. 2018;36:1780-1787.

4. Rouch L, Cestac P, Hanon O, et al. Antihypertensive drugs, prevention of cognitive decline and dementia: a systematic review of observational studies, randomized controlled trials and meta-analyses, with discussion of potential mechanisms. CNS Drugs. 2015;29:113-130. doi:10.1007/s40263-015-0230-6 
5. Levi Marpillat N, Macquin-Mavier I, Tropeano AI, et al. Antihypertensive classes, cognitive decline and incidence of dementia: a network meta-analysis. J Hypertens. 2013;31:1073-1082. doi:10.1097/HJH.0b013e3283603f53

6. Hajjar I, Levey A. Association between angiotensin receptor blockers and longitudinal decline in tau in mild cognitive impairment. JAMA Neurol. 2015;72:1069-1070. doi:10.1001/jamaneurol.2015.1001

7. Hajjar I, Brown L, Mack WJ, Chui H. Impact of angiotensin receptor blockers on Alzheimer disease neuropathology in a large brain autopsy series. Arch Neurol. 2012;69:1632-1638.

8. Fournier A, Oprisiu-Fournier R, Serot JM, et al. Prevention of dementia by antihypertensive drugs: how AT1-receptor-blockers and dihydropyridines better prevent dementia in hypertensive patients than thiazides and ACE-inhibitors. Expert Rev Neurother. 2009;9:1413-1431. doi:10.1586/ern.09.89

9. Wang J, Ho L, Chen L, et al. Valsartan lowers brain $\beta$-amyloid protein levels and improves spatial learning in a mouse model of Alzheimer disease. J Clin Invest. 2007;117:3393-3402. doi:10.1172/JCI31547

10. Li J, Culman J, Hörtnagl H, et al. Angiotensin AT2 receptor protects against cerebral ischemia-induced neuronal injury. FASEB J. 2005;19:617-619. doi:10.1096/fj.04-2960fje

11. Faure S, Chapot R, Tallet D, Javellaud J, Achard JM, Oudart N. Cerebroprotective effect of angiotensin IV in experimental ischemic stroke in the rat mediated by AT(4) receptors. J Physiol Pharmacol. 2006;57:329-342.

12. Kehoe PG. The coming of age of the angiotensin hypothesis in Alzheimer's disease: progress toward disease prevention and treatment? J Alzheimers Dis. 2018;62:1443-1466. doi:10.3233/JAD-171119

13. Wiesmann M, Roelofs M, van der Lugt R, Heerschap A, Kiliaan AJ, Claassen JA. Angiotensin II, hypertension and angiotensin II receptor antagonism: roles in the behavioural and brain pathology of a mouse model of Alzheimer's disease. J Cereb Blood Flow Metab. 2017;37:2396-2413. doi:10.1177/0271678X16667364
14. Barthold D, Joyce G, Wharton W, Kehoe P, Zissimopoulos J, Shimosawa T. The association of multiple anti-hypertensive medication classes with Alzheimer's disease incidence across sex, race, and ethnicity. PLoS ONE. 2018;13(11):e0206705. doi:10.1371/journal. pone.0206705

15. Marcum ZA, Hohl SD, Gray SL, Barthold D, Crane PK, Larson EB. Patient perceptions of antihypertensive use as a dementia prevention strategy: a mixed-method analysis of a web-based survey. J Alzheimers Dis. 2019;68:523-529. doi:10.3233/JAD181080

16. Marcum ZA, Hohl SD, Gray SL, Barthold D, Crane PK, Larson EB. Brain health and dementia prevention: a mixed-method analysis. Am J Health Behav. 2019;43:300-310. doi:10.5993/ AJHB.43.2.7

17. Girdler-Brown BV, Dzikiti LN. Hypothesis tests for the difference between two population proportions using Stata. South Afr J Pub Health. 2018;2:63-68.

18. Hajjar I. Postural blood pressure changes and orthostatic hypotension in the elderly patient. Drug and Aging. 2005;22(1):55-68. doi:10.2165/00002512-200522010-00004

19. Aikens JE, Nease DE, Klinkman MS. Explaining patients' beliefs about the necessity and harmfulness of antidepressants. Ann Fam Med. 2008;6:23-29. doi:10.1370/afm.759

20. Barclay TR, Hinkin CH, Castellon SA, et al. Age-associated predictors of medication adherence in HIV-positive adults: health beliefs, self-efficacy, and neurocognitive status. Health Psychol. 2007;26:4049. doi:10.1037/0278-6133.26.1.40

21. Mishra SI, Gioia D, Childress S, Barnet B, Webster RL. Adherence to medication regimens among low-income patients with multiple comorbid chronic conditions. Health Soc Work. 2011;36:249-258. doi:10.1093/hsw/36.4.249
Patient Preference and Adherence

\section{Publish your work in this journal}

Patient Preference and Adherence is an international, peer-reviewed, open access journal that focusing on the growing importance of patient preference and adherence throughout the therapeutic continuum. Patient satisfaction, acceptability, quality of life, compliance, persistence and their role in developing new therapeutic modalities and compounds to optimize clinical outcomes for existing disease

\section{Dovepress}

states are major areas of interest for the journal. This journal has been accepted for indexing on PubMed Central. The manuscript management system is completely online and includes a very quick and fair peer-review system, which is all easy to use. Visit http:// www.dovepress.com/testimonials.php to read real quotes from published authors. 